

\title{
Using Genetic Algorithm for Winter Maintenance Operations: Multi Depot K- Chinese Postman Problem
}

\section{Dr. İbrahim Zeki Akyurt}

Istanbul University, Istanbul, Turkey | e-mail: zekiakyurt@ gmail.com

\section{Dr. Timur Keskintürk}

Istanbul University, Istanbul, Turkey | e-mail: tkturk2010@gmail.com

\section{Dr. Çağatay Kalkancı}

Istanbul Metropolitan Municipality, Istanbul, Turkey|e-mail: cagatayk@ mail.com

Volume 5 No 1 (2015) ｜ ISSN 2158-8708 (online) ｜ DOI 10.5195/emaj.2015.69 | http://emaj.pitt.edu |

\section{Abstract}

This study deals with the winter maintenance operations in Istanbul, Turkey. The assignment and routing of winter service vehicles are discussed. The starting points of the study are the high cost of winter maintenance activities, decreased budget, high numbers of vehicles and routes to service. In this respect, the problem was modeled as multi depot k-Chinese postman problem, a type of arc routing problem. This mathematical model was solved by genetic algorithm. For comparison, the current solution, Clarke and Wright Algorithm and Sweep Algorithm were used.

\section{$(\mathrm{cc}) \mathrm{BY}$}

New articles in this journal are licensed under a Creative Commons Attribution 3.0 United States License.

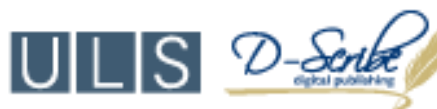

This journal is published by the University Library System of the University of Pittsburgh as part of its D-Scribe Digital Publishing Program, and is cosponsored by the University of Pittsburgh Press. 


\section{Using Genetic Algorithm for} Winter Maintenance Operations: Multi Depot KChinese Postman Problem

\author{
Dr. İbrahim Zeki Akyurt \\ Dr. Timur Keskintürk \\ Dr. Çağatay Kalkancı
}

\section{Introduction}

Winter conditions are among the factors influencing our daily life directly. Snow and ice experienced in winter months diminish friction co-efficiency on roads and affect traffic flow, and generate an unsafe environment for land and air traffic and cause unfavorable social and economic effects. Ice and snow have rather big influences on roads. Errors made in road maintenance in winter months lead to frequent closing of roads and therefore lead to economic losses (Sherif and Hassan, 2004). Another effect caused by ice and snow is the increased accident risk (Norrman, Eriksson and Lindqvist, 2000; Eriksson and Norrman, 2001). Anti- icing is the application of solid, liquid or pre-heated chemicals to the ground prior to the snow falling. Anti-icing is the most frequently preferred method for snow removal (Ahmetzade, Y1lmaz, and Y1lmaz, 2007; Allison and Bernard, 2004; Kuloğlu and Kök, 2005).

In general terms, Turkey, which is located in a subtropical zone in the Mediterranean macroclimatic region, is under the influence of different types of air masses. In the winter time, Turkey stays under the influence of the polar based frontal system and in the summer time it is under the influence of the tropical-based frontal system, and it receives plenty of rain in spring (March and April) and fall (October to January) which coincides in the progress and regression periods of the said air masses. Precipitation in this period in general is in the form of rain in the seafronts and sections close to the seafronts, and they are in the form of sleet or snow in the inner region of the high sections. Moreover, during these periods, snow falling on the high sections of the Eastern Black Sea and the Eastern Anatolian Region are affected, and it is observed that it paralyzes the life on occasion. Furthermore, both structures of precipitation occurring in these periods and their formation in unexpected times other than the seasonal normal, lead to high disaster rates (Sever, 2008).

Istanbul is the most crowded city in this country with a similar climate and has the most prevalent industrial organizations and businesses. In this sense, it is an industrial, commercial, cultural, and educational center. When it is considered that 12 million people travel every day for various reasons in Istanbul, it is clear that life, gets to nearly a stop because of adverse weather conditions which can also lead to important losses to the economy of the country. We don't have exact figures for the economic loss amounts caused by adverse weather conditions in Istanbul, nevertheless, if the research conducted by the ITO (Istanbul Chamber of Industry) is considered, the effect on the economy caused by the snow storm experienced in January 2004 was at least 1 trillion TL.

Despite the significance of snow clearing, sanding and salt spreading, the number of studies conducted on this matter is rather low. Even in countries where these problems are shown among the important problems and despite the immense spending done, these problems are not studied extensively. In 1971 Marks and Stricker focused on vehicles providing public service and opened the snow clearing collection problems to discussion. Liebling (1973), handled snowplow routing by a two-stage procedure which is raw and good planning. Cook and Alprin (1976) attempted to solve the routing problem due to capacity limitations of salt spreading vehicles in an urban field. The main purpose was to minimize the time required for the salt spread to a certain road section. Tucker and Clohan (1980), generated a general computer model for urban SRP simulation. It was targeted that characteristics of snow clearing vehicles and snow storm were simulated by a series of parameters, and a routing was determined for effective snow plowing.

Lemieux and Campagna (1984), discussed processing in single tank, single vehicle SRPs. Haslam and Wright (1991) suggested a multipurpose algorithm method for snow clearing processing problem in the rural environment. The problem was defined to include minimum cost of the snowplow vehicles and to cover the total distance. Campbell and Langvein (1995), suggested a snow clearing problem as a multi sourced problem in a two-phase algorithm way. Golbaharan (2001), studied a multi-depot snow clearing processing problem by time windows; and in the model, the route for each snow vehicle starts and ends at the same depot. This problem was formulated to include a limited series and solved by a column generation algorithm. Perrier, Langevin, and Amaya (2008), have suggested a formulation and two-step solution based on mathematical 
optimization techniques for directing snow maintenance vehicles in urban areas. Fu, Trudel, and Kim (2009) have developed real-time optimization model for evaluating alternative resources for winter roads and maintenance processes. In the study of Dali (2009), a sequential constructive algorithm way was suggested for determining the routes of snow vehicles in a multi-depot network. Grupta et al. (2010) have conducted a shift planning project study for optimal work force for clearing snow and ice in Minnesota.

In this study, assigning of snow maintenance vehicles which take part in winter maintenance work in Istanbul and the scheduling of these vehicles were discussed. Such a model is included as multi-depot k-Chinese postman problem among arc routing problems (ARP). In this respect, a mathematical model of multi-depot k-Chinese postman problem (k-CPP) will be focused, which is specific to the situation and is the subject of the next section.

In the third section, the genetic algorithm will be shown for the solution of the generated mathematic model. Genetic algorithm phases, specific to the model, will be discussed. In the fourth section, data on the model regarding winter maintenance activities in Istanbul province will be shown. The fifth section encompasses the previous three sections. Istanbul province winter maintenance activities were modeled as multi-depot k-Chinese postman problem and solved by Genetic Algorithm and two other algorithm methods. The current solution and solving methods were compared in terms of cost.

\section{Problem Formulation}

The problem discussed in the study was a multidepot k-Chinese postman problem, which is a type of ARC routing problem. Arc routing problems plan to generate the shortest route with the lowest cost enabling to reach different points and return to the start point again (Gupta and Krishnamurti, 2003). The Chinese postman problem, defined by Mei-KoKwan in 1962 attempts to determine the most effective route for a postman to distribute the mail received from the post office and to return to the post office with the shortest walking distance during mail distribution. The Chinese postman problem is based on starting from a certain start point and to generate the shortest route with the condition that each point on the route is stopped at once at least one time (Ahuja, Magnatni, \&Orlin, 1993). In addition to handling arcs instead of nodes, Chinese postman problem is different from traveling salesman problem since it includes Euler tour as a basis. If in the Chinese postman problem a Euler tour is not achieved, it is necessary that it should go by the arcs more than once for tour completion. In a postman problem, if an Euler tour is present, the number of arrivals to a point must equal to the number of departures from that point. In case the postman cannot repeat an arc corresponding to a point, this point should be seen to have a double degree or the number of arcs arriving to this point should be seen as double.

The purpose of the Chinese postman problems is to minimize the total cost of passing at least once from all arcs by allowing passage from an arc more than one time. The linear programming model of Chinese postman problems is as follows:

$$
\begin{aligned}
& \min \sum_{i=1}^{n} \sum_{j=1}^{n} c_{i j} x_{i j} \\
& \sum_{j=1}^{n} x_{i j}-\sum_{j=1}^{n} x_{j i}=0 \quad \forall i \in V \\
& x_{i j}+x_{j i} \geq 1 \quad \forall(i, j) \in A \\
& x_{i j} \geq 0 \text { and integer } \quad \forall i, j \in V
\end{aligned}
$$

Equation 1 is a fitness function and minimizes the number of visited arcs. The constraint for the entry numbers and exit numbers of each arc is included in equation 2 . There must be at least one visit for each arc (Equation 3) and all variables must be positive integer numbers.

When the Chinese postman problem is attempted to be solved by more than one postman or vehicle, the problem $\mathrm{k}$ is called the Chinese postman problem ( $\mathrm{k}-\mathrm{CPP}$ ). The $\mathrm{K}$ number of vehicles with a $\mathrm{C}$ capacity leave from the depot and visit all arcs with a positive demand and carry out the tours so that the vehicle capacity will not be exceeded. The objective is to make tours with minimum cost, in other words with minimum total distance. In the graph, $\mathrm{G}=(\mathrm{V}$, $\mathrm{E})$; $\mathrm{V}$ represents the point group and $\mathrm{E}$ represents the arc group. 0 is the depot. The number of vehicles can be determined beforehand or it can be variable as well. Each arc $(i, j)$ has a cost $\left(c_{i j}\right)$ and demand $\left(d_{i j}\right)$. Each arc in the problem can be visited as many times as desired.

$$
\begin{aligned}
& \min \sum_{k \in K} \sum_{i, j \in V} c_{i j} x^{k}{ }_{i j} \\
& \sum_{k \in K, j \in V} x^{k}{ }_{i j}-\sum_{k \in K, j \in V} x^{k}{ }_{j i}=0 \\
& \sum_{k \in K} x^{k}{ }_{i j} \geq 1 \quad \forall i \in V \backslash\{0\}, \forall j \in V \backslash\{0\} \\
& \sum_{j \in V} x^{k}{ }_{0 j}=K,
\end{aligned}
$$


$\sum_{i \in V} x^{k}{ }_{i 0}=K$

$\sum_{i \in S_{k}} \sum_{j \in S_{k}} x^{k}{ }_{i j} \leq\left|S_{k}\right|-2 \quad \forall S_{k} \subset V, S_{k} \neq \emptyset$,

$x^{k}{ }_{i j} \in\{0,1\} \quad \forall(i, j) \in A, \forall k \in K$.

Equation 7 expresses constraint of passing from each arc at least once. Equation 8 and 9 indicate the requirement that all vehicles start the tour from a depot and end up at the same depot. The 10th constraint shows that the route of each vehicle should not have an empty group as well as equal 2 less than the element number of the $\mathrm{S}$ group (visited nodes), which is a sub group of V. Secondly, it contains departures from a depot and returns to the same depot.

The application problem is modeled as a multi depot k-Chinese postman problem which is a type of Chinese postman problem developed with multi depots and multi vehicles. The mathematical model of our problem can be explained this way. We have used the first group then the route process for the genetic algorithm and other heuristics. Accordingly, relevant routes are assigned to the current depots. Studies in the literature use different techniques to perform this. In our study, each route is assigned to the closest depot. When this process is performed, routes where each depot is going to provide a service are determined and the problem is turned into a k-CPP for each depot. k-CPP formulation (Equation 5 - Equation 10) is used for each depot in our application problem by using the same formulation, and optimization of the total of solutions of these sub problems is the objective. Different techniques are used in the studies in the literature for achieving this. As $V g=\{1, \ldots, n\}$ n number of depots, $T i$, k-CPP objective function belonging to depot $i$, the objective function in our problem can be expressed as follows.

$\min \sum_{i \in V_{g}} T_{i}$, Multi Depot k-CPP

The distance of $c_{i j}$ in $\mathrm{k}-\mathrm{CPP}$ formulation is different for different $i$ and $j$ groups. As $\mathrm{G}=(\mathrm{Vg} \mathrm{U} \mathrm{Va}, \mathrm{A})$ being a graph, $\mathrm{Vg}=\{1, \ldots \ldots, n\}$ expresses $\mathrm{n}$ number of depots, $\mathrm{Va}=\{n+1, \ldots \ldots, n+s\}, s$ number of arcs, for each $j$, if $j \in \mathrm{Vg}$, in other words, if it is returned from an $i$ arc to a $j$ depot, $c_{i j}=d_{i j} . d_{i j}$ is the distance of the road between $i$ and $j$ points. If $j \in \mathrm{Va} ; c_{i j}=d_{i j}+c_{i}$. Here $c_{j}$ is the total tour distance calculated according to the number of tours that a vehicle has to take in $j$ arc.

\section{Genetic Algorithm Model for Snow Maintenance Problem}

Genetic algorithm, population based metaheuristic algorithm, which gives good results for similar problems is used to solve our problem. Genetic algorithms, started by Michigan University Faculty Member J. Holland during 1960s, are developed for solving some nature problems which are difficult to be solved or impossible to be solved by deterministic methods (Mitchell, 1995). Genetic algorithm, instead of generating a single solution for problems, generates a solution group made of different solutions. Thus, many points are evaluated in the search space at the same time and as a result of this, possibility to reach an optimal or near optimal solution increases. Solutions in the solution group are independent from each other completely. Each one of them is a vector on multidimensional space (Tuong-Quan and et al., 2009).

In our model, the population can be considered as a set of books that every book is a chromosome that represents one solution. Every page of book represent a depot and every row including the route of a specific vehicle (Figure 1).

In our problem, the chromosome structure given in Figure 1 was used. Since Istanbul is situated on two different continents, a chromosome group, made of as many pages as the number of depots for European and Anatolian (Asia).

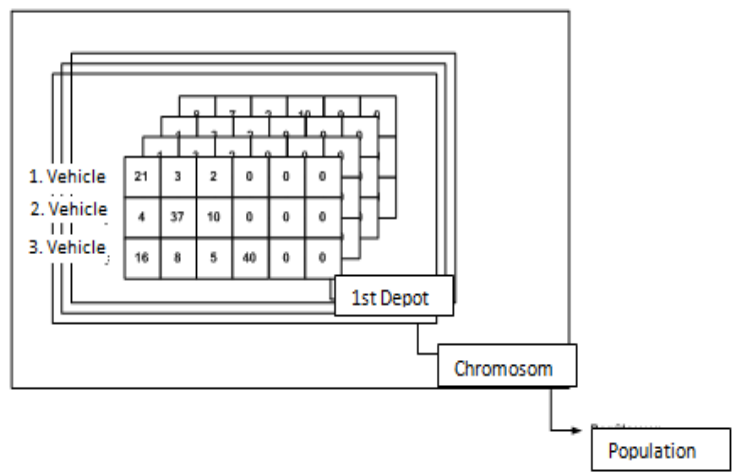

Figure 1: Population representation of multi depot ARP and CPP problems in GA. 
A separate matlab .*m file was used for the estimation of relevance values. The total distance calculated with adding up the distance from depot to the arc, the distance at salting operations on the arcs and return distance to the depot. Moreover, for respect to distance constraint, a penalty function is added and it is enabled that solutions remain in the feasible solution area.

Roulette wheel selection method was used for selecting operator. The method was created in a separate matlab file and selection process of the population sent to this file in iteration. Chromosomes belonging to the better fitness value were multiplied, and chromosomes having the worse fitness value were removed from the population.

A different method was developed for crossover operator. Firstly, two chromosomes are chosen randomly. Secondly, again choosing the depot randomly that the same depot of two chromosomes exchange. Thus, there was no reason for coming up with unfeasible solutions and preparing of required control mechanisms (Figure 2).

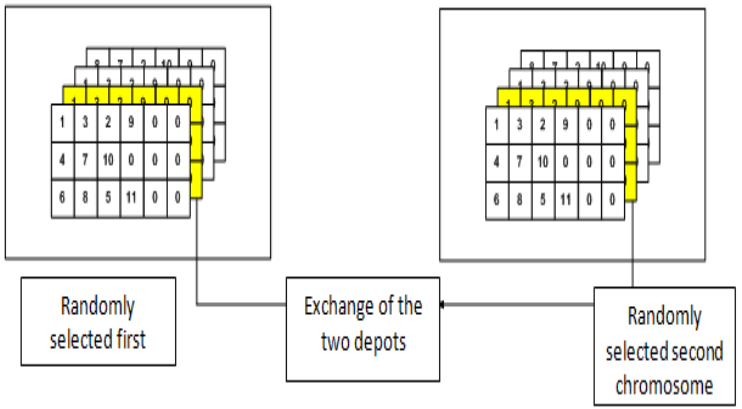

Figure 2: Crossover operator developed for CPP in GA.

Generally, crossover operator is used according to certain crossover rate. Candidate chromosomes are produced according to this and compared with parent chromosomes so better chromosomes are left in the generation. This crossover process can be done in many different ways, and in our study it is done without using the crossover rate. Accordingly, as much as the population size, a new individual is created by randomly selected parent chromosomes and their fitness values are calculated. Individuals as many as the size of the population, which has higher fitness among the parent chromosomes and the entirety of the new individual chromosomes, are sent to the next operator as the individuals of the new generation.

Another GA, mutation, operator used to avoid local optimums. Different processes are developed specific to the problem for mutation. These are divided into two groups. First: A change made in one of the tours belonging to the same depot in a chromosome; the second one is changes made among different routes in the same depot. Two different local search procedures within two groups were applied according to the mutation possibility. One of these is random exchange and the other is insertion mutation. In the random exchange mutation, values of the genes in two positions that are selected randomly are changed reciprocally (Figure 3 ).

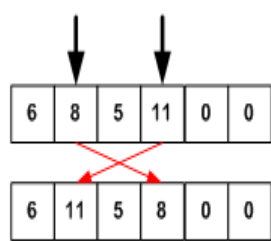

Random exchange

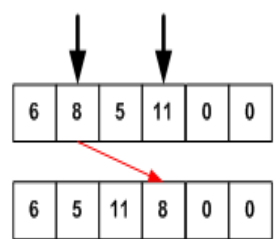

Insertion
Figure 3: Mutation operators used in GA for CPP: the same route.

When they are visited in the same tour, the positions of the two routes visited in the relevant route are changed reciprocally. In insertion mutation, on the other hand, the value of a gene in a position that is selected randomly, is added to an interval in another position that is selected again randomly.

When they are visited in the same route, visiting order of a course in a route is changed. Same mutation operators are also applied between different routes (Figure 4).

When the mutation possibility is provided, one of these four different operators is applied with equal chances.

\begin{tabular}{|c|c|c|c|c|c|}
\hline 6 & 8 & 5 & 11 & 0 & 0 \\
\hline 7 & 15 & 9 & 3 & 2 & 0 \\
\hline 13 & 1 & 0 & 0 & 0 & 0 \\
\hline 12 & 4 & 14 & 10 & 0 & 0 \\
\hline \multicolumn{7}{|c|}{} \\
\begin{tabular}{|c|c|c|c|c|c|}
\hline 14 & 8 & 5 & 11 & 0 & 0 \\
\hline 7 & 15 & 9 & 3 & 2 & 0 \\
\hline 13 & 1 & 0 & 0 & 0 & 0 \\
\hline 12 & 4 & 6 & 10 & 0 & 0 \\
\hline
\end{tabular}
\end{tabular}

Random exchange

\begin{tabular}{|c|c|c|c|c|c|}
\hline 6 & 8 & 5 & 11 & 0 & 0 \\
\hline 7 & 15 & 9 & 3 & 2 & 0 \\
\hline 13 & 1 & 0 & 0 & 0 & 0 \\
\hline 12 & 4 & 14 & 10 & 0 & 0 \\
\hline \multicolumn{7}{|c|}{} \\
\begin{tabular}{|c|c|c|c|c|c|}
\hline 8 & 5 & 11 & 0 & 0 & 0 \\
\hline 7 & 45 & 9 & 3 & 2 & 0 \\
\hline 13 & 1 & 6 & 0 & 0 & 0 \\
\hline 12 & 4 & 14 & 10 & 0 & 0 \\
\hline
\end{tabular}
\end{tabular}

Insertion
Figure 4: Mutation operators used in GA for CPP: Between different routes. 


\section{Istanbul Example for Snow Maintenance}

In our study, salting operation in winter maintenance activities in Istanbul was discussed. The problem was limited with primary routes. For Istanbul, which is divided into two main regions as European and Asian, two sub problems were created in our model. There are 3 depots and 28 primary routes in the European side, and there are 4 depots and 20 primary routes in the Anatolian side. Coordinate data of these depots are shown in Table 1. Indication of the depots of the Anatolian side on a map is given in Figure 5.

Table 1: Coordinates of The Depots

\begin{tabular}{|l|c|c|l|c|c|}
\hline \multicolumn{3}{|c|}{ EUROPEAN SIDE } & \multicolumn{3}{c|}{ ASIAN SIDE } \\
\hline DEPOT & $\mathbf{X}$ & $\mathbf{Y}$ & DEPOT & $\mathbf{X}$ & Y \\
\hline Edirnekapı & 41.0865 & 45.45696 & K.Bakkalköy & 42.5268 & 45.38550 \\
\hline Maslak & 41.8372 & 45.53625 & Kartal & 43.1289 & 45.31139 \\
\hline Tüyap & 38.4003 & 45.45409 & Hekimbaşı & 42.4925 & 45.47295 \\
\hline & & & Ömerli & 44.4440 & 45.49329 \\
\hline
\end{tabular}

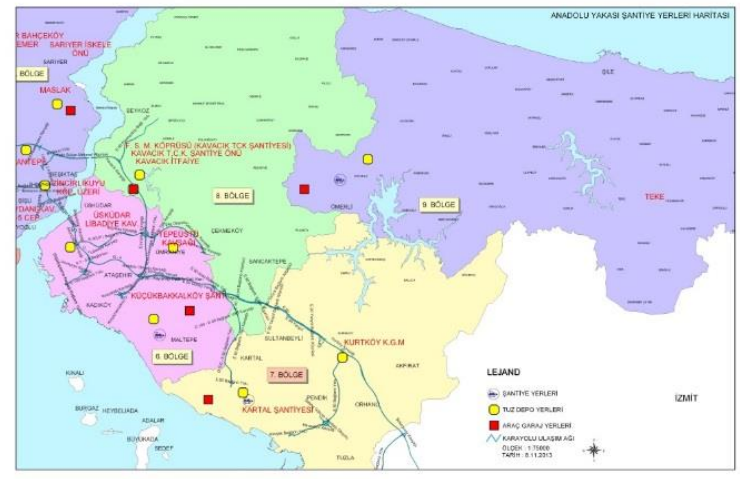

Figure 5: Anatolian Side depots' locations.

Other data about the problem are starting and ending point coordinates of the routes, vehicle capacities, distance constraints and current solution information.

Primarily, distance information is determined according to the real road distances. The geography information system and Arc GIS program were used. With the condition that the Anatolian and European sides are handled separately, the distance matrices generated in a two groups. There are two different kind of matrices that the first one is distances between primary routs and the second one is distances between depots and primary routes. Depending on the number of depots and routes for the European Side, a distance matrix of a dimension of 28 to 28 and 3 to 28 routes were established. These matrices for the Anatolian Side were determined as 20 to 20 and 4 to 20 . An example of matrix can be seen in Table 2 .

Table 2 : Example of distances matrix (European Side: Depots - routes starting point) $(\mathrm{km})$.

\begin{tabular}{|l|c|c|c|c|c|}
\hline & $\ldots \ldots$ & $\mathbf{X}_{\mathbf{1 1}}$ & $\mathbf{X}_{\mathbf{1 2}}$ & $\mathbf{X}_{\mathbf{1 3}}$ & $\ldots . .$. \\
\hline Edirnekapı & $\ldots$ & 11,1 & 19,1 & 19,5 & $\ldots$ \\
\hline Maslak & $\ldots$ & 23,6 & 31,6 & 32 & $\ldots$ \\
\hline Tüyap & $\ldots$ & 15,6 & 7,5 & 15,7 & $\ldots$ \\
\hline
\end{tabular}

There are different types of salting vehicles, and their speed capacities are close to one another. According to this, vehicles are homogenous and their salt capacities are 7.500 kilograms. The vehicles spread until salt runs out. When salt is finished or when there is no more salt needed vehicles go to the depot.

There are some assumptions for the problem;

- The vehicles are homogenous; in other words their salt capacities are the same.

- The vehicles tour around in the same route(s) until the salt runs out, and return to the depot.

- Since the vehicle running out of salt during salting will be returning to the depot after completing their routes, the estimated tour number (total salt amount of vehicle(s)/salt need in a route for one tour) is rounded up.

- The vehicles return to the depot they leave from.

- Fuel capacities of the vehicles are enough to complete their tours and for returning to their depots.

\section{Application}

As a solution method of the model, genetic algorithm was selected. For comparison with classical algorithm, Clarke and Wright saving algorithm, and sweep algorithms were used. These algorithms have used for vehicle routing problems in literature. Algorithms were modified specifically to our problem. All codes, including genetic algorithm, were written by MATLAB R 2009a program.

The parameters used in the application of genetic algorithm to our problem are number of iterations, population size, and mutation probability. As a result of the tests, it showed that genetic algorithm found the best solution between 200 and 500. However by considering this characteristics of the algorithm, which does not guarantee the optimum and making a progress jump in advance iterations, the iteration number was determined to be 1000 . 
Population size in literature is between 20 and 100 in general. In our study, it was considered that a population size of 30 would be sufficient as a result of the performed tests. Although increasing this size would enable the finding of the best value, in an early iterations; it could increase the algorithm completion time due to the operations. A series of studies was performed for mutation possibility and different values were tested. These values are in turn 1\%,3\% and 5\%. It was observed that $5 \%$ found faster and good results. For assigning routes to depots, a method used frequently in literature, assigning of all routes to the closest depot technique was used. In the initial population, except for one chromosome, a method for assigning to all routes a single vehicle was used. Current solution of the set up for one chromosome was assigned as the initial solution.

Clarke and Wright savings method was developed by Clarke and Wright in 1964. It was started by estimating cost saving of each customer dual and continued by adding a customer between the two customers. This method was used in the study for comparison purpose. The saving method has been continuing to be developed up until today (Laporte, 1992) in many researches like the researches of Gaskell (1967) and Yellow (1970).

The sweep method was suggested by Gillet and Miller in 1974 for the solution of small and large ARP problems (Laporte, 1992; Düzakın and Demircioğlu, 2009). In the sweep algorithm, the nodes for distribution are shown on a polar coordinate system, and the depot is positioned as the center of the polar coordinate system (Nureahyo et al., 2002).

Developed genetic algorithm Matlab codes were run in a computer with Pentium Dual Core processor, 4 GB memory and 120 GB hard disk characteristics. The results are shown in Table 3 and Table 4.

Table 3 : Comparison of the solutions.

\begin{tabular}{|c|c|c|c|c|c|c|c|c|c|c|}
\hline & \multirow[t]{2}{*}{ Cunent } & \multirow[t]{2}{*}{ |Sireep | } & \multirow{2}{*}{$\begin{array}{l}\text { Difi. } \\
\left(y^{\prime}\right)\end{array}$} & \multirow{2}{*}{$\begin{array}{c}c d \\
\mathbb{W}\end{array}$} & \multirow{2}{*}{$\begin{array}{l}\text { Difi. } \\
(\%)\end{array}$} & \multicolumn{4}{|c|}{ G } & \multirow{2}{*}{$\begin{array}{l}\text { Difi. } \\
\left(y^{\prime}\right)\end{array}$} \\
\hline & & & & & & $\begin{array}{l}\text { The } \\
\text { norst }\end{array}$ & Median & $\begin{array}{l}\text { The } \\
\text { best }\end{array}$ & $\begin{array}{l}990 \% \text { Confidence } \\
\text { interval }\end{array}$ & \\
\hline Europe & 4132,6 & 4057,8 & 0,02 & 3999,8 & 3,21 & 4001,3 & 3992,1 & 3988,9 & [3991,1, - 3993,0] & 3,40 \\
\hline Asia & 2914,6 & 2872,9 & 0,01 & 2889,9 & 0,85 & 2828,1 & 2823,7 & 2822,4 & {$[2823,1-2824,3]$} & 3,12 \\
\hline Iotal & 7047,3 & 6930,7 & 0,02 & 6889,7 & 2,24 & 6829,5 & 6815,8 & 6811,3 & {$[681.14,8-68816,9]$} & 3,28 \\
\hline $\begin{array}{l}\text { CPU } \\
\text { time }\end{array}$ & - & 4 & - & 4 & - & - & 4,56 & - & - & - \\
\hline
\end{tabular}

Table 4 : Comparison of solution (\%).

\begin{tabular}{|l|l|l|l|l|}
\hline & Current & $\begin{array}{c}\text { Swreeping } \\
\text { Algorithm }\end{array}$ & C \& W & GA \\
\hline Europe & 1,035 & 1,016 & 1,002 & 1,000 \\
\hline Asia & 1,032 & 1,017 & 1,023 & 1,000 \\
\hline Total & 1,033 & 1,017 & 1,011 & 1,000 \\
\hline
\end{tabular}

When the results are examined, it is observed that genetic algorithm generates better results than the current solution and other classical algorithms. Both the European and Anatolian and in total, objective function values, were better for genetic algorithm. The result found for the European Side was $3.4 \%$ better than the current solution; $3.12 \%$ better for the Anatolian Side; and in total $3.28 \%$ better than the current solution. The sweep algorithm was less unsatisfactory, it can be stated that it was not successful. Although Clarke and Wright saving algorithm, on the other hand, could make a progress worth of mentioning, it was again insufficient in the Anatolian Side and in total.

Sum of GA improvements was determined to be $3.28 \%$. Its equivalent is $231,5 \mathrm{~km}$. It was observed that annual intervention number was 15 in the meetings held with the institution. As a result of the progress made according to this, total annual distance improvement is: $15 \times 231,5=$ $3.472,5 \mathrm{~km}$.

Distributions of GA solutions for the European and the Asian Sides are shown as box graphics in Figure 6. In the graphs, distribution of the results around the median is given as boxes, and max and min values estimated by medians are shown by the low and upper limits. According to this, it can be stated that GA results are very close to one another, and it can be said that the deviation in the European Side and the extreme values in the Asian Side are within acceptable limits. Confidence interval with $99 \%$ possibility is estimated to be 3.991,14 and 3.993,07 for the European Side, and it is estimated to be $2.823,18$ and $2.824,31$ for the Asian Side.

Figure 6: Box graphics of GA solutions of the problem.

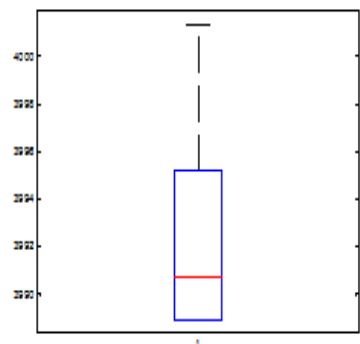

Europe

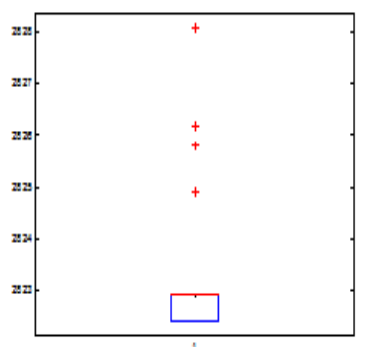

Asia 
When it is viewed in terms of cost evaluation; main cost items of the vehicles working in winter maintenance are;

- Fuel used by the vehicles

- Depreciation value of the vehicles

- Annual maintenance value of the vehicles

- Values paid to the drivers of the vehicles and assistants

- General expenditures.

The vehicles working in winter maintenance work run 1.200 kilometers. As a fuel value, $3.0 \mathrm{lt} / \mathrm{km}$ consumption was considered, and fuel value was accepted to be $4 \mathrm{TL} / \mathrm{lt}$. Depreciation value was accepted to be $100.000 \mathrm{TL}$, maintenance value 25.000 TL, driver value 3.900 TL, and general expenditure was accepted to be 10.000 TL. By dividing these numbers to the annually run 1.200 kilometers, expenditure for each 1 kilometer is found.

$\checkmark \quad$ Fuel expense: $12 \mathrm{TL} / \mathrm{km}(3,00 \mathrm{lt} * 4 \mathrm{TL})$

$\checkmark$ Depreciation: 83,30 TL/km ( $100.000 \mathrm{TL} / 1.200$ $\mathrm{km})$

$\checkmark \quad$ Maintenance amount: 20,83 TL/km (25.000 TL / $1.200 \mathrm{~km})$

$\checkmark \quad$ Driver amount: $26 \mathrm{TL} / \mathrm{km}(2 * 4 * 3.900 \mathrm{TL} / 1.200$ $\mathrm{km})$

$\checkmark$ General expenditure: $8.33 \mathrm{TL} / \mathrm{km}$ (10.000 TL / $1.200 \mathrm{KM})$

$\checkmark$ TOTAL: $150,46 \mathrm{TL} / \mathrm{km}$

As a result of the conducted study, it was found that a total of 150,46 TL spending is made for 1 kilometer. When it is multiplied by $3.472,5$ kilometers, which is found as improvement, this amount comes to $522.472 \mathrm{TL}$, and this equals to the number 12.000.000 TL annually, in other words, this equals to approximately $4,35 \%$ of spending made for winter works.

\section{CONCLUSION}

In this study, routing of the vehicles for primary routes in Istanbul Province winter maintenance works was examined. The problem was modeled as the arc routing problem, which is a type of vehicle routing problems. In terms of constraints and objective function, it was set up as Chinese postman problem, which is one of arc routing problems. The problem was divided into two sub problems as Europe and Asia, and it was solved as multi depot for each continent. The current solution was compared with the genetic algorithm, Clarke and Wright saving algorithm and sweep algorithm. When the results were examined, it was observed that the best value for both continents and total was obtained by the genetic algorithm, and for each intervention, the improvement was 231,5 kilometers, and 3,28\%. Since 15 interventions were faced annually, the equivalent of this progress annually was determined to be $3472,5 \mathrm{~km}$. The benefits of such a progress per intervention and annually are not limited with a progress made per kilometer; but also it has direct and indirect benefits as well such as decreasing traffic load, reducing work force hours, time of intervention and decreasing environmental pollution.

The study, handled in the winter maintenance content, can be extended to road construction and maintenance, traffic service and safety, garbage collection and similar areas, and improvement can be spread to primarily the traffic problem in Istanbul, which has been growing for years.

Since the study has provided favorable results in Istanbul in general, it can be applied to other regions. 


\section{REFERENCES}

Ahmetzade, P., Yılmaz, M. ve Yilmaz, M. (2007). Kar ve buz ile mücadele etmek amacıyla geliştirilen daha etkili ve ekonomik yeni yöntemler. 7. Ulaştırma Kongresi Bildiri Kitab1, ss. 186-195, İstanbul: Eylül, 2007

Ahuja, K. R., Magnatni, T. L. ve Orlin, J. B. (1993). Network flows: Theory, algorithms and applications, Prentice Hall, New Jersey.

Allison E. K. and Bernard N. S. (2004), Effects of highway deicing chemicals on shallow unconsolidated aquifers in

Ohio-Final Report, Scientific Investigations Report 2004-5150, p. 199.

Campbell, J. F. and Langevin, A. (1995). Operations management for urban snow removal and disposal. Transportation Research- A, 29 (5): 359-370.

Cook, T. M. and Alprin, B. S. (1976). A snow and ice removal in an urban environment. Management Science, 23: $227-234$.

Dali, Z. (2009). Optimization of vehicle routing for plowing and snow disposal. $\mathrm{Y}$. Wang, P. Yi, S. An, H. Wang (Editors). Proceedings of the 9th International
Conference of Chinese Transportation Professionals. ICCTP 2009: Critical Issues in Transportation System Planning, Development, and Management, Harbin, China, ss. 27382744.

Eriksson, M. and Norrman, J. (2001). Analysis of station locations in a road weather information system. Meteorological Applications, 8: 437-448.

Fu, L., Trudel, M. and Kim, V. (2009). Optimization winter road maintenance operations under real time information. European Journal of Operational Research, 196: 332ᄀ341.

Golbaharan, N. (2001). An application of optimization to the snow removal problem - A column generation approach. Ph. D. Thesis, Linköping University, Linköping, Sweden.

Gupta, D., Tokar-Erdemir, E., Kuchera, D., Mannava, A. K. ve Xiong, W. (2010). Optimal workforce planning and shift scheduling for snow and ice removal. Technical Report, Industrial and Systems Engineering Program, Department of

$$
\text { Mechanical Engineering, }
$$

University of Minnesota. 
Haslam, E. and Wright, J. R. (1991). Application of routing technologies to rural snow and ice control. Transportation Research Record, 1304: $202-211$.

Kuloğlu N. and Kök B. V. (2005). Karayollarında kar ve buz mücadelesinde kullanılan tuzun beton asfalt kaplamaya etkisi. Frrat Üniversitesi Fen ve Mühendislik Bilimleri Dergisi, 17 (1): 87-96.

Lemieux, P. F. and Campagna, L. (1984). The snow plowing problem solved by a graph theory algorithm. Civil Engineering Systems, 1: 337-341.

Liebling, T. M. (1973). Routing problems for street cleaning and snow removal. İçinde, Deininger, R. (Editör), Models for environmental pollution control, ss. $363-374$.

Marks, H. D. and Strieker, R. (1971). Routing for public service vehicles. ASCE Journal of the Urban Planning and Development Division, 97: 165-178.

Mitchell, M. (1995). Genetic algorithms: An overview. Complexity, 1 (1): 31-39.
Norrman, J., Eriksson, M. and Lindqvist, S. (2000). Relationships between road slipperiness, traffic accident risk and winter road maintenance activity. Climate Research, 15: 185-193.

Perrier, N., Langevin, A. and Amaya, C. A. (2008). Vehicle routing for urban snow plow operations. Transportation Science, 42: 44-56

Sever, R. (2008). Aşırı kar yağışlarının afete dönüşmesini engellemek için alınması gereken bazı önlemler. 5. Dünya $\mathrm{Su}$ Forumu Bölgesel Hazırlık Süreci: DSI Yurtiçi Bölgesel Su Toplantıları. Kar Hidrolojisi Konferansı Bildiri Kitabı, ss. 173-183.

Sherif, A. and Hassan, Y. (2004). Modelling pavement temperature for winter maintenance operations. Canadian Journal of Civil Engineering, 31: 369378.

Tucker, W. B. and Clohan, G. M. (1979). Computer simulation of urban snow removal. Transportation Research Board, Special Research Report Number 185, ss. 293-302. 
Tuong-Quan V., Hyoung-Seok, K., Hyo, S. C.,

Doan, N. D. and Byung-Ryong, L.

(2009). A study on optimization of fish

robot maximum velocity using the

combination of genetic - hill climbing

algorithm. ICCAS-SICE, ss. 2280-

2285. 